\title{
THE STUDY OF THE CULTURAL- MORPHOLOGICAL FEATURES OF PHYTOPATHOGENIC FUNGUS ACREMONIUMSP. 502
}

\author{
G. V. Tsekhmister
}

Representatives of Cucurbitaceae family are valuable crops and rank third by acreage in Ukraine. During the growing season they are affected by negative influence of different phytopathogens that results in considerable loss of farms. Representatives of Acremonium genus can cause disease to plants of Cucurbitaceae family [15]. The disease was first described in 1994 in Spain on melon plants [10]. The following year it was recorded in Texas on melon and watermelon plants [12] and in 1996 it was established that the causative agent was Acremonium cucurbitacearum [18]. It is also know that the representative of Acremonium genus caused the similar disease of melons observed in California [11]. In 2002 in Italy A. cucurbitacearum, A. crotonigenum and A. Sclerotigenum were also isolated from collapsed melons [16]. It is also know that $A$. sclerotigenum Gams, which has a saprophytic type of nutrition, under certain conditions (high concentration of salt in soil) can act as vascular parasite of cucumber plants [7].

There are no data about the spread of the disease in Ukraine. In 2011 S. P. Nadkernychnyi isolated Acremonium sp. 502 strain from sick cucumber plants that were grown in the conditions of covered soil. We have confirmed its pathogenicity to cucumber plants [8].

The development of pathogenic fungi largely depends on the conditions created by biotic and abiotic factors. The main abiotic factor affecting the spread and development of cucumber diseases is temperature. The activity of each kind life activity is possible only in certain temperature ranges. Temperature optimum in most is the determining factor for the dominance of a particular type in agrocenoses. For a long period the pathogen can exist without showing activity, and only at optimal temperature it will manifest its parasitic effect [4]. For example, potato phytopathogen Phytophthora infestans develops within the range of $2-26^{\circ} \mathrm{C}$, with an optimum at 18 $21^{\circ} \mathrm{C}$. It is known that temperature optimum for corn cob white rot causative agent Fusarium poae is $24-26^{\circ} \mathrm{C}$ [5].

In many cases, the lesion of Cucurbitaceae family with diseases is associated with abiotic environmental conditions, especially temperature $[9 ; 13 ; 14]$. In 1982 W. D. Gubler [17] noted that the disease of seedlings of that family caused by A. cucurbitacearum was lower at $17^{\circ} \mathrm{C}$ and much higher at $27^{\circ} \mathrm{C}$, with an optimum at $24^{\circ} \mathrm{C}$.

Another equally important factor is the $\mathrm{pH}$ of the medium in which the fungus develops. For each strain of pathogenic microorganisms there are certain optimal limits of $\mathrm{pH}$. This factor not only influences the growth and development of the fungus, but also its ability to produce different metabolites that affect the plant [1]. Many fungi are tolerant to a wide range of medium $\mathrm{pH}$. Thus, it is known that Pénicillium variabelis, Fusarium bullatum and $F$. oxysporium can grow within 2.0-11.0 pH limits [3].

Taking into account the above, the goal of our work was to study certain culturalmorphological features of Acremonium sp. 502 at different culture conditions.

Materials and methods. The paper used pathogenic for cucumbers strain of fungi of Acremonium genus, isolated from sick cucumber plants grown in the conditions of covered soil. Strain virulence was previously confirmed on cucumbers of Koroliok variety. Fungus culture was kept on slant wort-agar (4 Balling degrees).

The research of culturalmorphological features of Acremonium sp. 502 was studied on wort-agar (WA), agarized Chapek synthetic medium (CA) and potato-glucose agar (PGA). Media were poured into Petri dishes. Incubated at $26 \pm 2^{\circ} \mathrm{C}$. On the 10th day radial growth rate of fungus colonies was noted. The description of colonies was performed on the day 28 , after the complete overgrowth of culture medium in a Petri dish by fungus mycelium. The colour of the colonies, their shape, surface type, thallus type, mycelium septate, view of 
the colony on the liquid medium, reproduction features, conidia and conidiophores size, sporification intensity.

The determination of temperature range of growth for Acremonium sp. 502 was performed using wort-agar. First, fungus was cultured at the temperature of $26 \pm 2^{\circ} \mathrm{C}$ within one day to initiate growth. The following day fungus cultivation continued at different temperature regimes: $8^{\circ} \mathrm{C}, 10^{\circ} \mathrm{C}, 18^{\circ} \mathrm{C}, 26^{\circ} \mathrm{C}$ and $34^{\circ} \mathrm{C}\left( \pm 2^{\circ} \mathrm{C}\right)$. On the 10th day colonies diameter was fixed in two mutually perpendicular directions and radial growth rate was determined by methods [6].

The research of optimum $\mathrm{pH}$ was determined by the diameter of fungus colony growth on wort-agar $(\mathrm{pH} 3.5 ; 4.5 ; 5.0 ; 6.0$; $6.5 ; 7.0 ; 7.5 ; 8.0 ; 8.5 ; 9.0 ; 9.5 ; 10.0 ; 10.5$; $11.0 ; 11.5 ; 12.0)$. Cultivation was carried out at the temperature of $26 \pm 2^{\circ} \mathrm{C}$. On the day 10 colonies diameter was fixed in two mutually perpendicular direct.

Repetition of the experiment quadruple. Statistical analysis of the results was performed by standard methods [2] using Microsoft Excel applications. At processing of experimental data mean-square deviation was calculated.

So, the analysis of the results of the study indicates the variability in Acremonium $s p .502$ growth depending on the composition of nutrition medium, temperature rate and medium $\mathrm{pH}$. By growth characteristic the fungus can be attributed to the group of slowgrowing. Differences in the size of conidia were fixed when grown in different media. It was established that the optimum temperature for Acremonium sp. 502 growth is $26^{\circ} \mathrm{C}$, optimal medium reaction for the development of the fungus - slightly alkaline $(\mathrm{pH} 8.5)$. 